\title{
A Case Study on Application of Traditional Architectural Heritage of Environmental Engineering in ancient Tamils in India
}

\author{
V. Pon.Panneerselvam \\ Pattukkottai polytechnic college, Pattukkottai - 614601 \\ Tamil Nadu, India \\ vppselva@yahoo.co.in
}

\begin{abstract}
The Scope of this Study revolves mainly around the importance and unique conceptual heritage of Tamil Nadu in the realm of Eco-friendly Architecture. Application of Environmental Engineering and Architectural aspects over the traditional Heritage of Tamil Nadu, forms the core of this study. It extends to investigate the salient features of the Eco-friendly Architecture and Environmental Engineering Heritage of the Tamils from the classical to late medieval periods of Tamil Nadu. In this paper, an attempt has been made to focus attention on awareness of Environment as a major determining factor for evolution of the ancient Architectural Heritage in early Tamil Nadu.
\end{abstract}

Key Words

Environment, Traditional, Tamil, Architecture, Heritage

\section{Introduction}

In India, Eco-friendly urban studies are still in their formative stage. Architects, Engineers, Scientists and Scholars are forced to seek the collaboration of other social sciences in related disciplines like Environmental Sciences, Management of Natural Resources, Application of Quality Technology, Geography, and Sociology, and Economics, par with the other developed countries. An area of enquiry, which proposes to study a certain facet of experience in space and time, needs a certain focus, a certain approach. This focus is all the more necessary in a field, where more than a single discipline is involved.

Study of Urbanization

Urban-history is the study of urbanization, of the evolution of urban centers in the span of time, and the Environment which promotes and retards such growth, and the Environment which towns generate in several related dimensions such as the natural Environment, the economic system, political apparatus, societal network and even the minds of men living in towns.

Urban Evolution

In History, the town has emerged with two primary characteristics: first, a limited space and secondly, a predominantly non-agricultural, particularly non-cultivating nature of its population.

This men-space ratio and occupational heterogeneity with their consequential relationships may be taken as the primary basis for differentiation between the town and the village. Obviously, the urban-centre comes into being within a rural setting. In an economy, which is primarily agrarian, viewing through this glass is of paramount importance.

Urban setup in Tamil Nadu

As noted before, Early Historic Heritage of Architecture and Environment of the Ancient Tamils and Tamil Nadu are yet to attract the due attention of scholars. This is the primary reason for the present study, besides, of course, the interest in ancient Tamil urban development processes

\section{Materials and Methods}

The present work covers mostly the first three centuries of the Christian era, generally accepted as the age of the Sangam. The Sangam Literature furnishes us quite considerable information. This paper gives explanative way of interpretation. Hence the explorative method is adapted to analyze the data collected. The main sources of the data are taken from the Sangam classical works, Bakthi Literature and Epics, The modern technical concepts of Architecture and Environmental Engineering disciplines and field data also considered. 


\section{Examination}

The scientific analytical understanding of the life style of ancient Tamil people yield extraordinary scientific data on the Environment. The fundamental, five Universal factors are very clearly studied and understood by them.

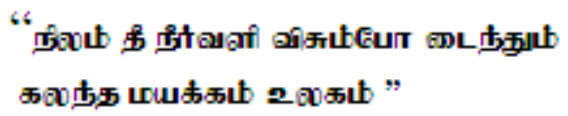

This Noorpa of Tholkappiyam explains the very formation of the World as an embodiment of these five Universal factors as precisely of the present geologists.

It also explains the observation and concept of the Tamils over the Universe as Environment Zone otherwise Environment Science, which is referred in the following verses of Purananuru with more characteristic details of these fundamental factors.

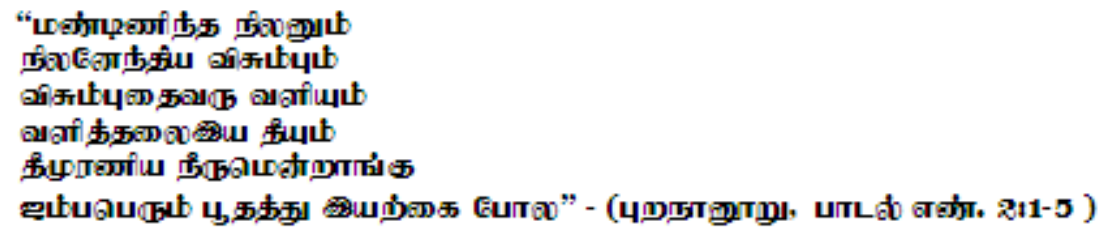

According to the concept of the ancient tamils, The Tamil Nadu was identified with the following Environmental classifications

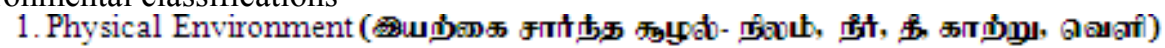

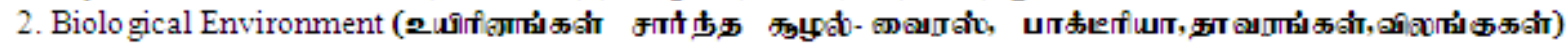
and

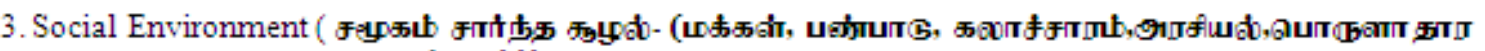
அஐைப்புகள்))

This Environment Zone is further classified as Muthal, Karu and Uripporul which are covering the landscape, claimate, Flora and Fauna and the Characteristic life style of the people concerned mainly with the four landscapes identified as Kurinji, Mullai, Marutham and Neithal. The pseudo desert that is seasonal desert formation of Tamilnadu as Palai is also dealt with. The Biosphere of the present day Environment Science is similar with the ancient concept of Thinai referred in Tholkappiyam.

In Tamil, the word biosphere is consisting of all the five fundamental units of the formation of the Universe, the soil, water, fire, wind, and space. They are inter-related, mingled with each other and having their origin from the other ones. Hence, they are inseparable and all powerful to create the world. It has been very well understandable from the following classical Tamil literary references

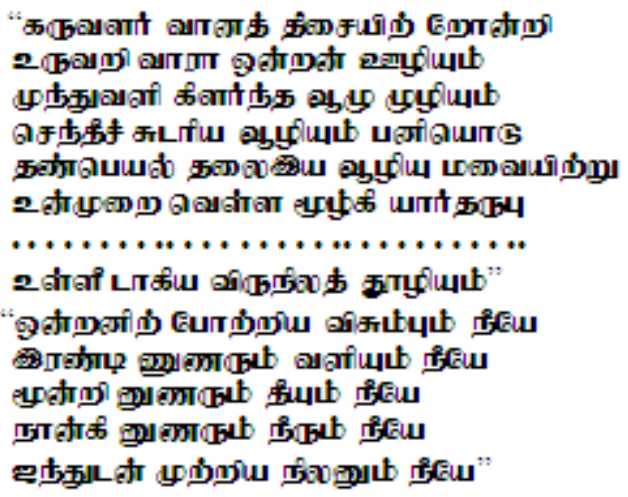

- (Ufurtob 112-12)

This observation and the inferences of the ancient Tamils over the Universal factors and their movement are exemplary.

They have also observed the character of the movement of the Sun and made a special note as "Parippu". The other characteristics of other Universal factors like wind, space etc., are also explained precisely in the following reference. 


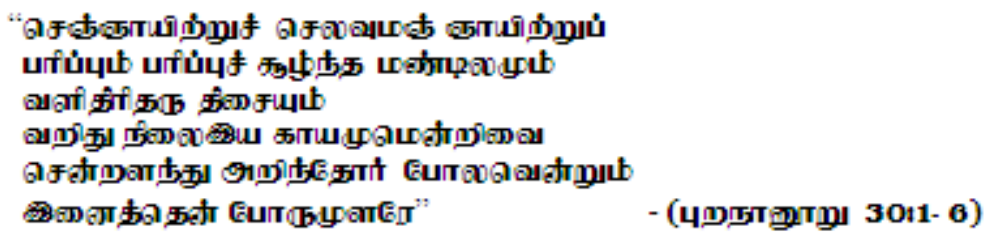

The difference between stars and planets are explained under,

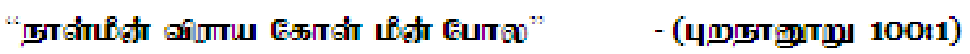

The full moon and the new moon forms of the lunar system are explained with the fort night classification by the ancient Tamil reference as follows.

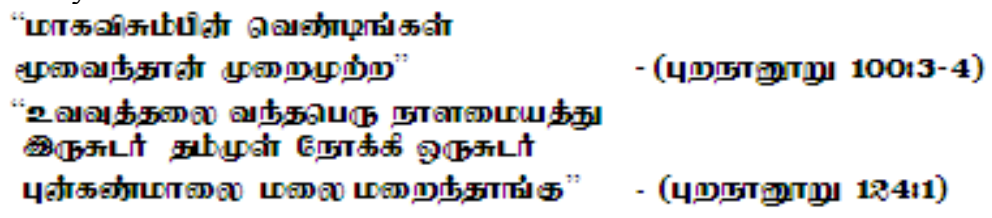

Like the present day observatory explorations, the ancient classical Tamil references explored the scientific ways and means of different space units like stars and their behaviours in accordance with the calendars. Explanations on different eclipses are also enumerated well.

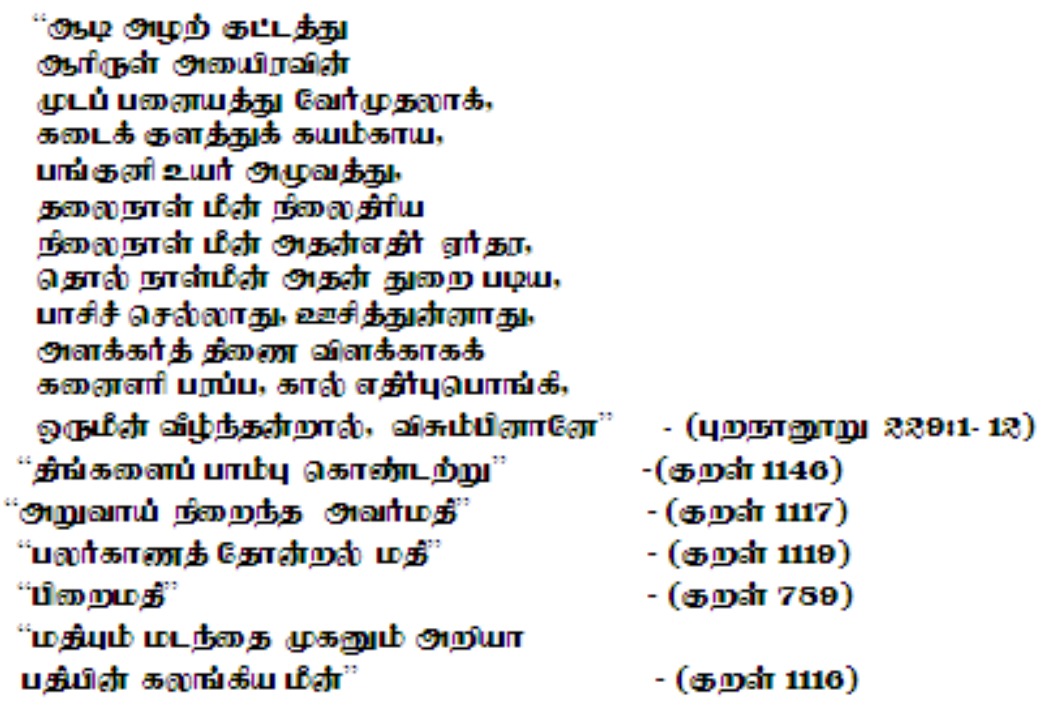

Deep analytical studies were also carried out intensely by the ancient Tamils and their observations clear the fact about the Flora and Fauna as follows.

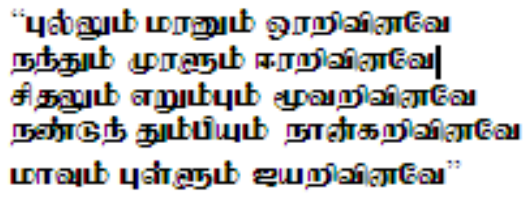

Plant Morphology is also very carefully noted down by the ancient Tamils dealing from seed, germination, sapling, roots, trunks, leaf, flowers, fruits, etc. In such a way plant taxonomy is also available with the ancient Tamil Literature. They are all explained widely over the awareness and clear understanding of the Tamils in the inter-relationship of the Flora, climate and the Environment. 
Importance of potable water:

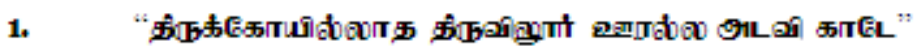

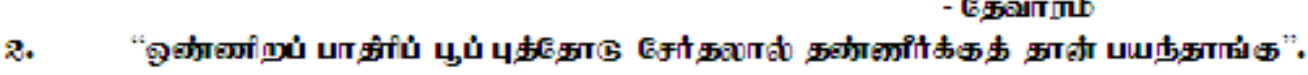

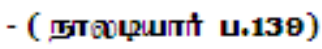

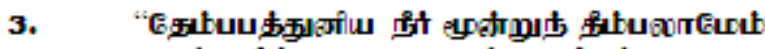

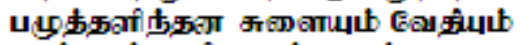

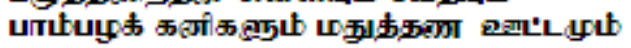
தாடம பழுத் நுளசில தவள யாடGே"

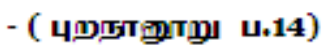

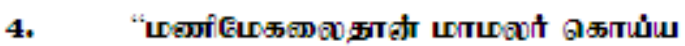

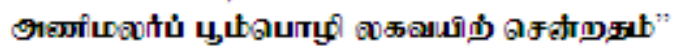

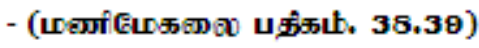

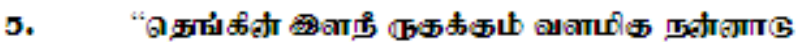

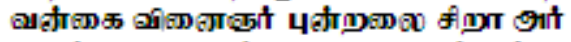

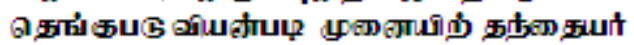

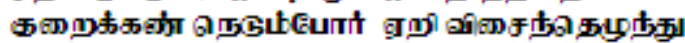

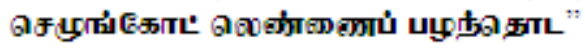

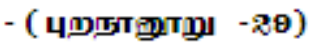

All these references points out the quality water consumed by the ancient Tamils.

a. In the pre-historic period, Tamilakam was inhabited by forest tribes of more or less nomadic habits.

b. At the dawn of the historic period, there existed and elaborate system of villages and towns partly lost in legend and partly proved by foreign authorities. The settlements were trading, administrative and agricultural, all of which had some emphasis on religion.

c. In all types, there was a certain ground plan or pattern. The basic provisions like water, food, shelter and dress are available at reach in every settlement in which nature was ever touched with soft feelings and hygiene was given more importance in all their consumptions which is confirmed by the following verses

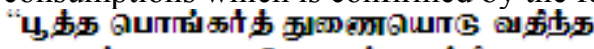

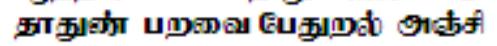

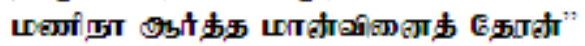

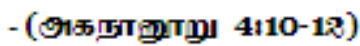

d. Water was treated with high respects and consider as the main source of any life which is referred as below.

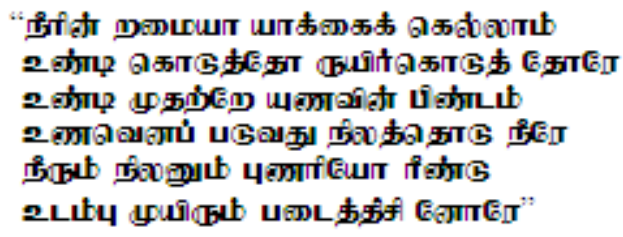

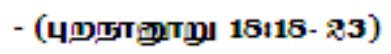

e. Although fire was treated with all honours, the forest fire was never entertained by the ancient Tamils which is referred here under.

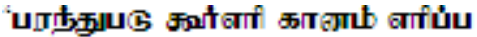

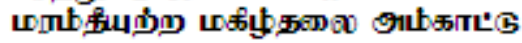

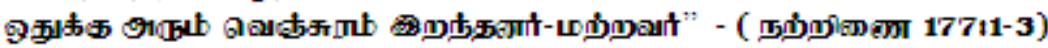

f. Like that deforestation is also not encouraged which can be noted from the following sangam works. 


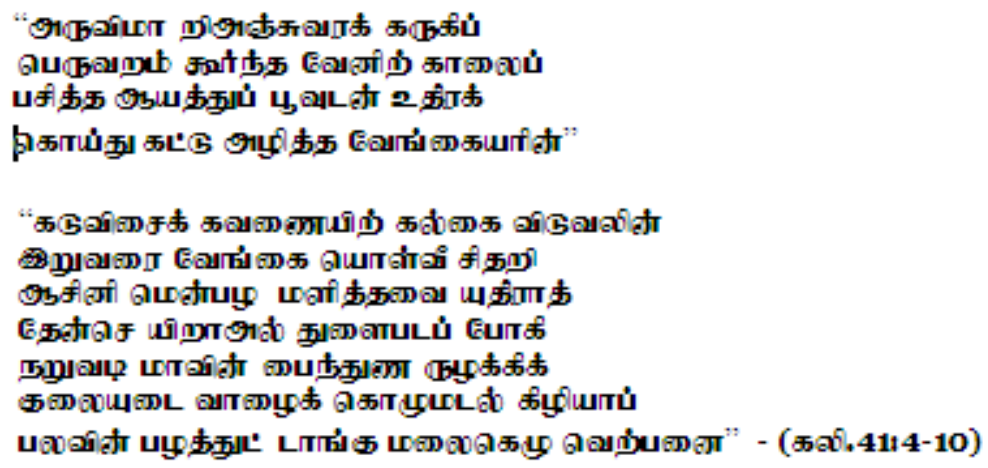

g) Simple but hygiene tasty food was preferred which is noted below.

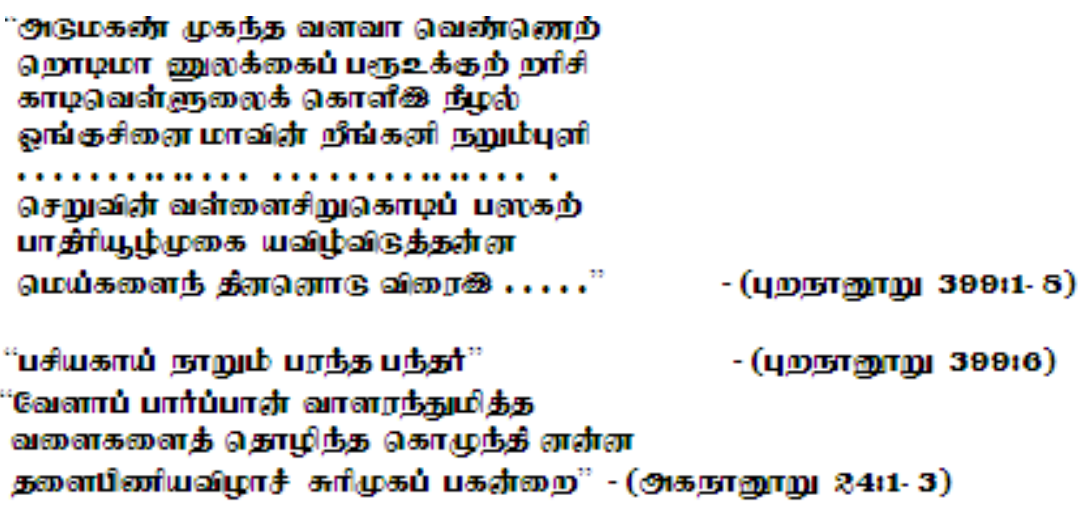

- (بуறБтறуறு 3өөн1- 8)

- (புறதாறூறு 3өө16)

h) A thorough and analytical awareness of the environment including the climate, flora and fauna are even referred in the ancient Tamil grammar Tholkappiam as follows.

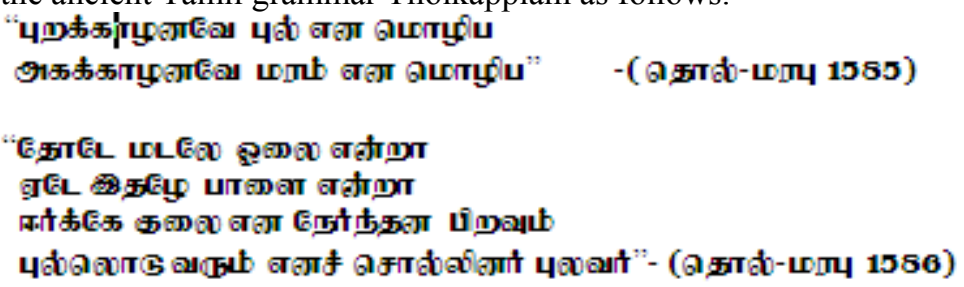

i) The eradication of pollution and liking of a pollution free environment was very much encouraged by the ancient Tamil as follow.

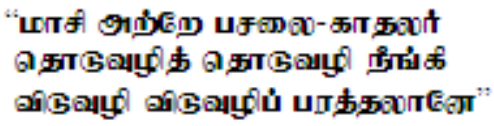

j) Non violence attitude was ever practiced by the ancient Tamils. Hence killing of even flora and fauna was also very much considered.

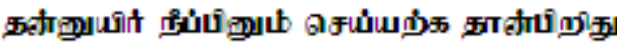

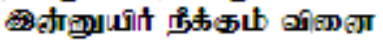

\section{- (๘றล่ 327)}

k) Environment up keeping enforced by religious practices among the ancient Tamils. Nature was worshiped. Flora like Neem, Papal, Banyan like trees, ocimum like plants, Arukampul grass and Karuda, Monkey, Cow like animals are also worshiped by Tamils. Therefore a sense of Environmental production was in practice among the ancient Tamils. More over they believe that the God is in everything and everywhere as omni present and omni potent.

1) Water management was sensibly carried-out by ancient Tamils with all careful and accurate management policies which can be inferred from the following references.

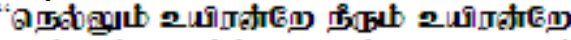

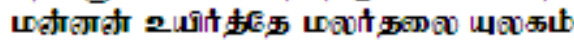

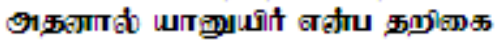

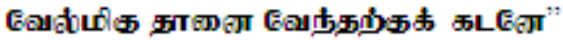

\section{-(புறதாறுறறு 18611-4)}




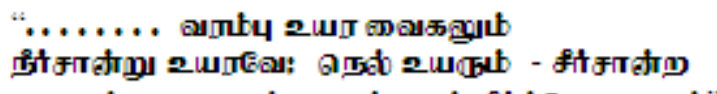

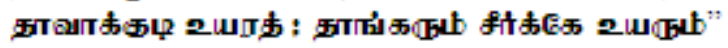

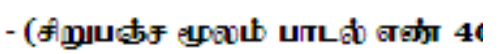

m) Proper maintenance of the landscape and the housing site of the ancient Tamils can be noted down from the following references.

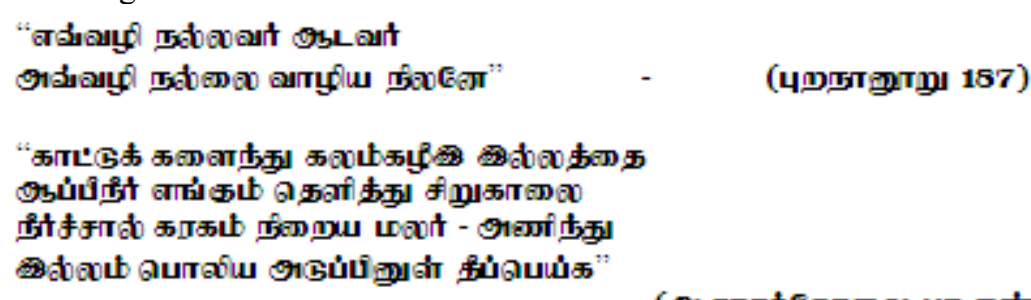

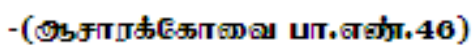

n) A thorough knowledge of the monsoons of Tamilnadu and the rain fall and the rain water harvesting was prevailed among the ancient Tamils which can be found from the following verses.

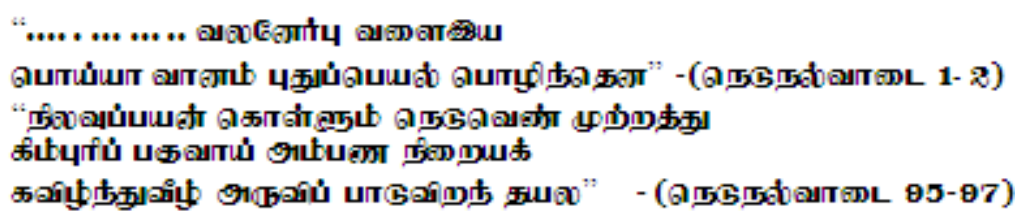

o) Classification of landscape in accordance with their characters are very well practiced by the ancient Tamils as Kurinji, Mullai, Marutham, Neithal and Palai. The quality like hard and soft are identified with the landscapes.

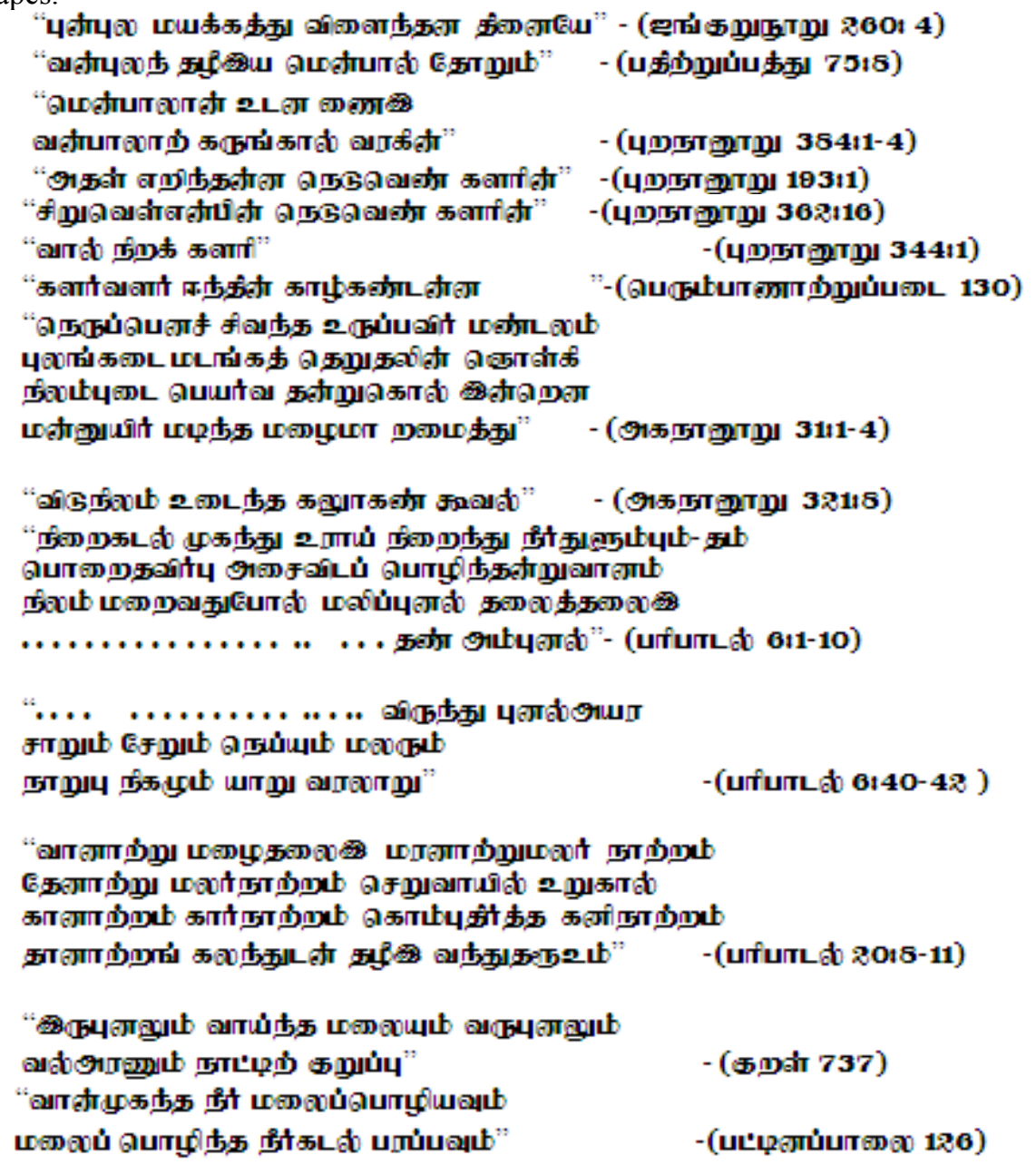

All the above references strengthen the points of this chapter and giving the emphasis establishing the architectural and environmental heritage of Tamil and its scientific qualities par with the modern era. 


\section{IV.CONCLUSION}

One cannot speak of environment without considering the impact on the lives of people. We have hundreds of small-scale and continuing environmental disasters taking place all around us. But we overlook them so long as they do not impact our lives or our lifestyles.

$>$ Architecture and Environmental Engineering were inseparable or complex formation among the ancient Tamils.

$>$ The experience of the Tamils with the nature or Environment is very rich which yield the modern green house effect to the lively hood of the ancient Tamils.

$>$ According to the experience and inherited knowledge ,they have classified the Environment as follows.

1. The space filled with different gases around the earth. (Vayu Mandalam)

2. Watery surface of the earth. (Neer Mandalam)

3. The crest of earth filled with soil, rocks, etc., (Nila Mandalam)

4. Different types of life (creatures) living in the above three surfaces (Uyir Mandalam)

These classification of the inherited knowledge prevailed among the ancient Tamil confirms the following Architecture and Environmental Engineering wisdom practiced in ancient Tamil Nadu.

- $\quad$ Analytical knowledge of the earth and making use of system.

- $\quad$ Keeping pollution free earth. Awareness of pollution etc.

- Usage of natural manures for their cultivation and agricultural efforts. Keeping the potential virgin soil.

- Minimized intervention in deforestation for having their Architectural structures.

- Afforest ration in and around housing either by belief or sense of beauty or religious practice.

- $\quad$ Awareness of pollution free water bodies. Having different water bodies for the domestic purposes like bathing, washing, building, drinking, cattle, etc.

- $\quad$ The drinking purpose water bodies were protected by engaging security.

- $\quad$ Awareness of the potable and domestic waters and the minimum usage.

- Knowledge of the pollution free air and usage by keeping away the industries in the outskirts of their residency.

- Awareness of fire and the technical know-hows of its usage.

- The soft approach over the nature -Environment can be very well understand from the inherited behavior of the ancient Tamil people which can be inferred from the following.

All the poems of Natrinai are on love. A recurrent theme in at least 50 per cent of the verses is the reference to trees.

Today, mankind has realized the key role trees play not only as a balm for sore eyes but also in our environment. We have done this with the aid of the most advanced technology.The poets of the Natrinai had no modern technology but had not only connected the role of trees to their well-being,but had observed even the minute variations of trees as the seasons change.

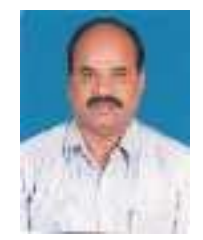

Received Ph.D degree on December1993 at Tamil University, Thanjavur, M.E (Environmental Engineering) on December1993 and B.E (Civil Engineering) at Annamalai University, Annamalai Nagar on June1990. Life member of "The Indian Society of Technical Education" New Delhi.

Member of "The Institution of Engineers" (Calcutta), Chartered Engineer (India).

He achieved certificate in CMI Level 5 Award in Management and Leadership (QCF) issued by CMI, London. Presented papers at National level seminars and published many papers in International journals with high impact factor and indexing. Expertise in Environmental Engineering Management and ideological personality in Civil Engineering fields 